\title{
sciendo
}

\section{Common Movement Patterns of the Jump Shot while Increasing the Distance from the Basket in Elite Basketball Players}

\author{
by \\ Nadja Podmenik ${ }^{1}$, Matej Supej ${ }^{1}$, Hana Debevec ${ }^{1}$, Frane Erčulj ${ }^{1}$
}

\begin{abstract}
The aim of this study was to examine chosen kinematic variables (duration of the shot, position of the centre of mass, position of the shooting hand, rotation of the shoulder axis) of successful shots and to describe differences in movement patterns in elite basketball players while increasing the distance from the basket during a jump shot. Our participants were three elite shooting guards who were all Slovenian national team and Euroleague players. They were shooting from three different distances $(3.75 \mathrm{~m}, 5.25 \mathrm{~m}$, and $6.75 \mathrm{~m}$ ); analysis included 90 successful shots. The kinematics of the entire body was analysed using the inertial motion capture suit. The main interest was on the transverse plane (direction $Y$ ), focusing on rotational movements and movements to the left and right. The results showed that the rotation of the shoulder axis in the transverse plane, with all three participants, was greatest $(p<.05)$ from the longest distance. Despite that graphs of individual players differed, deviation to the left was most significant while shooting from the largest distance for all participants. Also the landing from the jump shot was on the left according to the origin. For example, the average deviation to the left for player no. 2 was $11.9 \pm 3.6 \mathrm{~cm}$ (the shortest distance), $12.6 \pm 4.7 \mathrm{~cm}$ (the middle distance), and $23.3 \pm 5.1 \mathrm{~cm}$ (the longest distance). Distance from the basket influenced the kinematics of the shot, especially from the longest distance. Along with the already well-known changes in the sagittal plane (direction $X$ and $Z$ ), this research provides information on changes in the transverse plane, which are also very important, especially while shooting from longer distances.
\end{abstract}

Key words: transverse plane, duration of the shot, position of the centre of mass and shooting hand, rotation of the shoulder axis.

\section{Introduction}

Shooting at the basket is one of the most important and most widely used elements of the basketball game (Hay, 1994; Wissel, 2004), while the jump shot was labelled as the most important shot in basketball (Hay, 1994) since some data suggest that half of all the points in a game are scored by the jump shot (Erčulj and Štrubelj, 2013; Tang and Shung; 2005). It is a complex and a technically demanding shot where the ball is being shot while in the air. For a successful shot, the most optimal conditions must be ensured at the time of ball release. Ball release variables are well known. It has been proven that basketball players do not maintain the same release conditions of the ball while shooting at the basket from different distances, where the ball's angle of release and release height decrease when we increase the distance (Miller and Bartlett, 1996; Okazacki and Rodacki, 2012; Satern, 1993), while the release speed of the ball increases (Miller and Bartlett, 1996). When the distance from the basket is increased, the vertical (Miller and Bartlett, 1993) and the horizontal angle on the basket decreases (Okazacki and Rodacki, 2012), while the course of the ball to the basket increases (Satern, 1993; Walters et al., 1990). The angle of entry into the basket depends on the angle of release, the release height, and the release speed and is one of the key factors that determine whether the shot is going to

1 - University of Ljubljana, Faculty of Sport, Ljubljana, Slovenia. 
be successful. The ball's vertical angle of entry into the basket allows for maximum deviation. If the angle is decreased, this angle of entry turns into an ellipsis up to the angle of $32.7^{\circ}$ when the diameter of the ball is larger than the projected diameter of the basket and a goal is, even theoretically, no longer possible.

Several previous studies investigated basketball shooting and average values of certain shooting variables, which were mostly related to the shooting arm. Some researchers (Elliot, 1992; Okazaki and Rodacki, 2012; Satern, 1993) also captured and analysed data from video recordings where the camera was positioned laterally relative to the study subjects. From that position it was determined what occurred during a shot at the basket in the sagittal plane. This single camera technique was unable to determine the movements occurring in the frontal and transverse planes.

Although there are a lot of studies providing data about the position of the shooting arm and other body segments in basketball, there is a lack of knowledge about elite basketball players. Participants of previous studies were usually low level players or very heterogeneus in terms of their experience and basketball skills (Button et al., 2003; Miller and Jackson, 1995; Oberle, 2003), gender (Elliott, 1992; Satern, 1993), and the playing position (Miller and Bartlett, 1996). Consequently our study includes elite basketball players who played the same position and therefore did not differ significantly when it came to the mentioned characteristics (gender, role, experience, effectiveness). We chose the sample of shooting guards because kinematic variables of shooting at the basket change most consistently with the shooting guards when the distance from the basket is increased (Miller and Bartlett, 1996; Walters et al., 1990) and also because shooting guards usually decide to shoot from a greater distance (Sampio et al., 2015), which is also one of the most important roles they have in the game. Previous research also shows a tight connection between the player's position and anthropometric (morphological) characteristics or, in other words, that these characteristics greatly differentiate between different types of basketball players (Carter et al., 2005; Erčulj and Bračič, 2010; Sampio et al., 2006). Nonetheless, we are aware that every basketball player is somehow unique and has their own style (technique) of the jump shot, which is adjusted to his psychophysical characteristics. The aim of this study was to analyse successful shots for each individual separately, provide values of chosen kinematic variables and at the same time find those changes which occur with all participants when the distance from the basket is increased. In our analysis we emphasised variables in mediolateral direction $(\mathrm{Y})$, which had been neglected in previous studies. Therefore, we analysed the following variables: the duration of the shot, the trajectory of movement of the shooting hand, the trajectory of movement of the centre of mass $(\mathrm{CoM})$ and the rotation of the shoulder axis in the transverse plane.

\section{Methods}

\section{Participants}

Three elite basketball players participated in the study, who at the time of the research, played an important role in the strongest European club competition - the Euroleague. All three participants were also members of the national team of Slovenia where they played the shooting guard position. The average age of participants was $29.3 \pm 4.04$ years, body height 188 $\pm 5.07 \mathrm{~cm}$, and body mass $86.9 \pm 5.47 \mathrm{~kg}$. One of them was left-handed, while the other shooting guards were right-handed. They signed a written consent form and voluntarily participated in measurements that were approved by the ethics committee and adhered to the latest amendments of the Declaration of Helsinki. Participants were not suffering from any previous injuries that could affect the results and the execution of shooting at the basket.

Measures

We used the inertial motion capture suit MVN "MVN Biomech Pro" (Xsens, Enschede, Netherlands; $120 \mathrm{~Hz}$ ) when analysing kinematic variables of the jump shot. Previous studies have shown that this type of equipment is appropriate for the analysis of athletic movements when short sequences of movement are considered (Krüger and Edelmann-Nusser, 2010; Supej, 2011). The measurements were simultaneously recorded using the camera Casio Exilim - F1 $(300 \mathrm{~Hz})$, which was set perpendicularly to the direction of the shot, at a distance of $7 \mathrm{~m}$ from the shooting hand (Figure 1). The camera helped determine the 
time of ball release. For the purposes of synchronization of both measuring systems, participants would hit the ground with their foot on the side of the camera before executing the shot.

The standard procedure before starting the measurement required properly installed equipment (Figure 2), the entry of anthropometric measurements of each individual participant, and the calibration. The calibration took place in three positions with participants barefoot. After the initial 10-min warm-up, players performed shots from three different distances on the centre line of the field, $1.5 \mathrm{~m}$ apart from one another. Every participant first shot the ball from the first distance $(3.75 \mathrm{~m})$, then from the second distance $(5.25 \mathrm{~m})$, and at the end from the third distance $(6.75 \mathrm{~m})$. Participants were given instructions to perform jump shots imitating game situation. Each participant first performed three warm up shots from each distance. In order for the participant to be fully concentrated on the shot, the ball was picked up by a third person, who would pass the ball from under the basket and also give the signal for the shot. The objective of participants was to score 10 shots from each distance. They were shooting in $10 \mathrm{~s}$ intervals, in order to prevent fatigue. Only "swish" scores, i.e. scores without touching the rim or backboard, were included into further analysis.

\section{Design and Procedures}

The full analysis included 90 successful shots, 30 from each distance. Measured data were entered into Excel (Microsoft, Redmond, USA) using our own program Moven 2 Excell (Supej, 2012). The shot was divided into three phases - a preparation phase, a jump phase and a followthrough phase, which is consistent with previous research (Lamb et al., 2010; Miller and Bartlett, 1996) and together represents the hole cycle of the shot. The preparation phase lasted from the moment of the downward movement to the moment when both feet left the ground (take-off). The jump phase lasted from the take-off to the ball release, that is, the moment when the ball left the hand. The follow-through phase lasted from the ball release to the moment when both feet touched the ground (landing).

The following variables were chosen: the duration of the shot, the position of the CoM in all three axes, the position of the shooting hand in all three axes and the rotation of the shoulder axis in the transverse plane presented in the whole cycle of the shot. For an easier understanding of the results, we placed the coordinate system in a way that the $\mathrm{X}$-axis was pointing to the direction of the side line towards the basket (anteroposterior direction), the $\mathrm{Y}$-axis was pointing to the direction of the baseline (mediolateral direction), and the Zaxis ran perpendicularly to the axes mentioned before (superior-inferior direction). When it came to the position of the CoM and the shooting hand, we chose the ankle of the pivot foot as the basis of the coordinate system. For an equal comparison of all participants, we changed the sign before the mediolateral direction when measuring the lefthanded participant. Angle $\alpha$ (Figure 1) represents the rotation of the shoulder axis in the transverse plane. We adjusted the formula in order to gain the same angle with the left-handed participant.

In order to facilitate graphic presentation of the shots, the data were interpolated using cubic splines (SRS1 Cubic Spline plug-in for Excel) in such a way that all the shots from the first to the last point of each phase matched according to the number of points. These interpolated phases of each shot were combined into one shot. The duration of the first phase constituted $60 \%$ of the duration of the shot, the duration of the second phase constituted $15 \%$, and the duration of the third phase constituted $25 \%$. The time of the ball release was set as time 0 .

\section{Statistical Analysis}

We processed the acquired data with the software package SPSS (version 18) (IBM, Armonk, New York). Initially, the data sets were analysed using descriptive statistics (mean \pm standard deviations) of the 10 successful shots of each participant from one distance. Statistically significant differences between the distances were analysed with repeated measures ANOVA. Shapiro-Wilk and Hartley tests confirmed data normality and homogeneity. When the assumption of sphericity was violated, the Greenhouse-Geisser or Huynh-Feldt correction was used. Estimated epsilon $(\varepsilon)$ indicated which was the proper correction. When differences were statistically different, we used the Bonferroni correction of multiple comparisons. This method clearly indicated between which distances the statistically significant differences occurred. The significance level was set at $p<0.05$. We used line 
charts for graphical representation of the analysed variables over the entire shot.

\section{Results}

All three participants scored more than $90 \%$ of shots from the shortest distance. One of them scored all 10 shots and the other two 10 out of 11 shots. From the middle distance two participants scored 10 shots out of 12 and the third one 10 out of 20 shots. From the longest distance they made 10 shots out of 12, 14 and 17 attempts. Figure 3 depicts the movement of the CoM of all three participants. On average, the length of the jump increased towards the direction of the basket during the entire cycle of the shot when the distance from the basket increased. This length ranged from 20.8 to $32 \mathrm{~cm}$ with the shortest distance, 34.8 to $38 \mathrm{~cm}$ with the middle distance, and 38.8 to $49.2 \mathrm{~cm}$ from the longest distance. All three participants showed a difference in the anteroposterior direction when it came to the shortest and longest distance in the moment of the take-off, the ball release, and the landing $(p<.05)$.

In the mediolateral direction, the highest number of differences occurred in the longest distance, especially with the first two players, where the difference was significant $(p<.05)$ in the moment of the take-off and ball release. Despite the statistically significant differences, the pattern of movement for player no. 3 was similar until the ball release, while after the ball release significant differences appeared. The average deviation to the left (according to the origin) was 2.8, 15.4 and $17.4 \mathrm{~cm}$ (the shortest distance), -4.9, 18.9 and $23.8 \mathrm{~cm}$ (the middle distance), and 6.4, 38.1 and $25.4 \mathrm{~cm}$ (the longest distance).

The curve of the CoM in the superiorinferior direction differed the most in the preparatory phase of the shot, where the CoM of the longest distance achieved the lowest point of the amplitude of movement in the shortest time. This was evident for players no. 2 and 3. Their movement pattern in the preparatory phase was much different when shooting from the shortest distance (Figure 2). The average maximum height of the CoM increased in two players when we increased the distance from the basket $\left(\mathrm{D}_{3.75}=\right.$ $70.7 \% ; D_{5.25}=71 \% ; D_{6.75}=71.8 \% ; D_{3.75}=73.5 \% ; D_{5.25}=$ $\left.74.7 \% ; \mathrm{D}_{6.75}=77.4 \%\right)$. A statistically significant difference $(p<.01)$ appeared only in one player. The third player reached the maximum height of the CoM when shooting from the middle distance $\left(\mathrm{D}_{3.75}=82.8 \% ; \mathrm{D}_{5.25}=84.2 \% ; \mathrm{D}_{6.75}=83.8 \%\right)$. It means that the maximum height of the CoM for the player who was $190 \mathrm{~cm}$ tall reached $157 \mathrm{~cm}\left(\mathrm{D}_{3.75}\right)$, $160 \mathrm{~cm}\left(\mathrm{D}_{5.25}\right)$ and $159 \mathrm{~cm}\left(\mathrm{D}_{6.75}\right)$. The same pattern could be recognized also for the height of the $\mathrm{CoM}$ at ball release and for the released arm (Table 1). According to the ball release, the maximum height of the CoM is achieved at different points of the curve. While shooting from the shortest and middle distance, all participants reached the maximum height of the CoM first, which was on the average .052, .085, .117 s (shortest distance) or .005, .034, .069 s (middle distance) before the ball release. While shooting from the longest distance, one of the participants achieved the maximum height of the CoM in .027 $\mathrm{s}$ before the release, while the other two participants achieved the peak after the release (.002 s; .027 s). Differences between the distances were significant $(p<.05)$ in all three players.

Table 1 shows the duration and the position of the shooting hand of each participant. Considering the duration, the part of the shot before the ball release got shorter when the distance was increased and was prolonged after the ball release. Statistical differences can be seen with all three participants between the shortest and the longest distance $(p<.01)$. The movement of the hand followed the same trend as the movement of the CoM. Differences $(p<.05)$ can be seen with all three participants between the shortest and the longest distance in the moment of the take-off, ball release, and landing in the direction of the basket (anteroposterior direction), at the time of the take-off and ball release in the lateral direction (mediolateral direction), and at the beginning of the shot with the up-down movement (superior-inferior direction). With the mentioned distances, the average difference in the direction of the basket was $21 \mathrm{~cm}$ (player 1), 5.1 $\mathrm{cm}$ (player 2), $12.8 \mathrm{~cm}$ (player 3) and $1.8 \mathrm{~cm}$ (player 1), $17.4 \mathrm{~cm}$ (player 2), $4.8 \mathrm{~cm}$ (player 3) in the lateral direction.

The rotation of the shoulder axis in the transverse plane (Figure 4) differs according to each player, but these differences between distances were similar with all three participants. The greatest difference can be seen in the preparatory phase (although player no. 2 performed a similar rotation at the beginning of 
the shots from all three distances), when the difference was considerably greater with the longest distance. The rotation had the highest value already in the initial formation or soon after the initial movement. Even though the differences decreased after the take-off, they were still significant $(p<.05)$ with all the players. At the time of ball release from the longest distance (D 6.75$)$, the rotation of the first player amounted to $40^{\circ}\left(\mathrm{D}_{3.75}=39^{\circ}\right)$, with the second player reaching $55^{\circ}\left(\mathrm{D}_{3.75}=50^{\circ}\right)$, and the third player to $12^{\circ}\left(\mathrm{D}_{3.75}=\right.$ $\left.6^{\mathrm{o}}\right)$.

Table 1

The average time and position of the shooting wrist in the specific moments.

\begin{tabular}{|c|c|c|c|c|c|}
\hline & & Duration (s) & $X(\mathrm{~cm})$ & $Y(\mathrm{~cm})$ & $\mathrm{Z}(\% / \mathrm{TV})$ \\
\hline \multicolumn{6}{|l|}{ Player no. 1} \\
\hline & D (m) & $\mathrm{M} \pm \mathrm{SD}$ & $\mathrm{M} \pm \mathrm{SD}$ & $\mathrm{M} \pm \mathrm{SD}$ & $\mathrm{M} \pm \mathrm{SD}$ \\
\hline \multirow[t]{3}{*}{ Beginning } & 3.75 & $-.94 \pm .074^{a}$ & $29.1 \pm 5.6$ & $-27.7 \pm 2.6$ & $58.6 \pm 0.85^{a}$ \\
\hline & 5.25 & $-.84 \pm .055$ & $31.6 \pm 5.5$ & $-28.3 \pm 2.3$ & $56.8 \pm 0.67$ \\
\hline & 6.75 & $-.75 \pm .089^{c}$ & $30.4 \pm 2.5$ & $-29.9 \pm 2.2$ & $55.9 \pm 1.27^{c}$ \\
\hline \multirow[t]{3}{*}{ Take-off } & 3.75 & $-.18 \pm .024^{\mathrm{a}}$ & $47.9 \pm 2^{\mathrm{a}}$ & $-18.8 \pm 1.1^{a}$ & $105 \pm 0.58$ \\
\hline & 5.25 & $-.13 \pm .009^{b}$ & $59.4 \pm 1.7 \mathrm{~b}$ & $-21.6 \pm 2.1^{b}$ & $105 \pm 0.31^{b}$ \\
\hline & 6.75 & $-.12 \pm .007 \mathrm{c}$ & $65.3 \pm 4.6^{c}$ & $-14.6 \pm 1.3^{c}$ & $104.2 \pm 0.82^{c}$ \\
\hline \multirow[t]{3}{*}{ Ball release } & 3.75 & 0 & $72.1 \pm 2.4^{\mathrm{a}}$ & $-17.6 \pm 2.6^{a}$ & $112.8 \pm 1.49$ \\
\hline & 5.25 & 0 & $84.4 \pm 3.1$ & $-23.7 \pm 2.5^{b}$ & $113.1 \pm 0.72$ \\
\hline & 6.75 & 0 & $89.2 \pm 8.5^{c}$ & $-13.6 \pm 2.5^{c}$ & $113.2 \pm 1.58$ \\
\hline \multirow[t]{3}{*}{ Landing } & 3.75 & $.11 \pm .029^{a}$ & $71.7 \pm 2.2^{\mathrm{a}}$ & $-15 \pm 5.3^{a}$ & $111.6 \pm 0.38^{a}$ \\
\hline & 5.25 & $.19 \pm .016^{\mathrm{b}}$ & $85 \pm 3.8$ & $-26.8 \pm 6.4^{b}$ & $110.8 \pm 0.48$ \\
\hline & 6.75 & $.27 \pm .009$ c & $94 \pm 19.3^{c}$ & $-15.4 \pm 5$ & $110.6 \pm 0.73^{c}$ \\
\hline \multicolumn{6}{|l|}{ Player no. 2} \\
\hline \multirow[t]{3}{*}{ Beginning } & 3.75 & $-.94 \pm .036$ & $33.3 \pm 2.2$ & $-20.9 \pm 1.4$ & $59.6 \pm 0.76^{a}$ \\
\hline & 5.25 & $-.89 \pm .061^{b}$ & $31.5 \pm 1.7 \mathrm{~b}$ & $-22.2 \pm 2.9^{b}$ & $57.5 \pm 0.81$ \\
\hline & 6.75 & $-.48 \pm .012^{c}$ & $48.6 \pm 1.3^{c}$ & $-8.2 \pm 1.6^{c}$ & $57 \pm 1.38^{c}$ \\
\hline \multirow[t]{3}{*}{ Take-off } & 3.75 & $-.24 \pm .012^{\mathrm{a}}$ & $50.6 \pm 2.2^{\mathrm{a}}$ & $-11.7 \pm 1.3$ & $103.3 \pm 0.47$ \\
\hline & 5.25 & $-.19 \pm .028$ & $60.2 \pm 1.9^{b}$ & $-11.9 \pm 1.5^{b}$ & $103.6 \pm 0.69$ \\
\hline & 6.75 & $-.19 \pm .01^{\mathrm{c}}$ & $66.3 \pm 2.2^{c}$ & $1 \pm 1.7 \mathrm{c}$ & $103.7 \pm 0.62^{c}$ \\
\hline \multirow[t]{3}{*}{ Ball release } & 3.75 & 0 & $74.6 \pm 2.9^{a}$ & $0.5 \pm 3.4$ & $112.7 \pm 1.11^{\mathrm{a}}$ \\
\hline & 5.25 & 0 & $85.8 \pm 4.4^{b}$ & $-0.5 \pm 2.2^{\mathrm{b}}$ & $115.3 \pm 3.03^{b}$ \\
\hline & 6.75 & 0 & $95.1 \pm 3.6^{c}$ & $19.6 \pm 2.7^{c}$ & $118.9 \pm 0.71^{\mathrm{c}}$ \\
\hline \multirow[t]{3}{*}{ Landing } & 3.75 & $.11 \pm .012^{\mathrm{a}}$ & $71.4 \pm 2.7^{\mathrm{a}}$ & $5.4 \pm 4^{\mathrm{a}}$ & $111.3 \pm 0.41$ \\
\hline & 5.25 & $.2 \pm .013^{\mathrm{b}}$ & $81.6 \pm 5.8^{\mathrm{b}}$ & $9.5 \pm 3.3^{\mathrm{b}}$ & $111.7 \pm 0.51$ \\
\hline & 6.75 & $.29 \pm .01^{\mathrm{c}}$ & $91.9 \pm 5.6^{c}$ & $35.6 \pm 3.7 \mathrm{c}$ & $112.2 \pm 0.81^{\mathrm{c}}$ \\
\hline \multicolumn{6}{|l|}{ Player no. 3} \\
\hline \multirow[t]{3}{*}{ Beginning } & 3.75 & $-1.14 \pm .079 \mathrm{a}$ & $23 \pm 1.9$ & $-19.7 \pm 1.4^{a}$ & $60.6 \pm 1.01$ \\
\hline & 5.25 & $-1.03 \pm .037^{\mathrm{b}}$ & $23.5 \pm 1.6$ & $-17.8 \pm 1.7^{b}$ & $60.7 \pm 1.79 \mathrm{~b}$ \\
\hline & 6.75 & $-.7 \pm .16^{c}$ & $22.2 \pm 4.3$ & $-13.9 \pm 0.8^{c}$ & $54.6 \pm 2.32^{c}$ \\
\hline \multirow[t]{3}{*}{ Take-off } & 3.75 & $-.26 \pm .013^{a}$ & $40 \pm 1.7$ & $-0.6 \pm 1.1^{a}$ & $109.1 \pm 0.96$ \\
\hline & 5.25 & $-.22 \pm .006^{b}$ & $40.2 \pm 1.8^{b}$ & $3.1 \pm 1.8$ & $108.8 \pm 0.63$ \\
\hline & 6.75 & $-.2 \pm .012^{c}$ & $42.5 \pm 2.1^{c}$ & $2.2 \pm 1.8^{\mathrm{c}}$ & $108.8 \pm 0.82$ \\
\hline \multirow[t]{3}{*}{ Ball release } & 3.75 & 0 & $70.1 \pm 4.6$ & $3.1 \pm 1.6^{a}$ & $123.3 \pm 1.72^{\mathrm{a}}$ \\
\hline & 5.25 & 0 & $71 \pm 2.6^{\mathrm{b}}$ & $8.4 \pm 3$ & $126 \pm 1.27$ \\
\hline & 6.75 & 0 & $75.8 \pm 3.3^{c}$ & $9.4 \pm 3.7^{\mathrm{c}}$ & $125 \pm 2.5$ \\
\hline \multirow[t]{3}{*}{ Landing } & 3.75 & $.24 \pm .012^{\mathrm{a}}$ & $78.1 \pm 5.8$ & $3.4 \pm 2.7^{a}$ & $109.6 \pm 0.63$ \\
\hline & 5.25 & $.31 \pm .009^{b}$ & $83.2 \pm 5.4$ & $11.8 \pm 4.4$ & $109.8 \pm 0.91$ \\
\hline & 6.75 & $.34 \pm .012^{c}$ & $90 \pm 7.8^{c}$ & $14 \pm 7.8^{c}$ & $109 \pm 1.08$ \\
\hline
\end{tabular}

$D$, distance $(m) ; a$, statistically significant differences between the shortest and middle distance;

$b$, statistically significant differences between the middle and longest distance; ${ }^{2}$, statistically significant differences between the shortest and longest distance. 


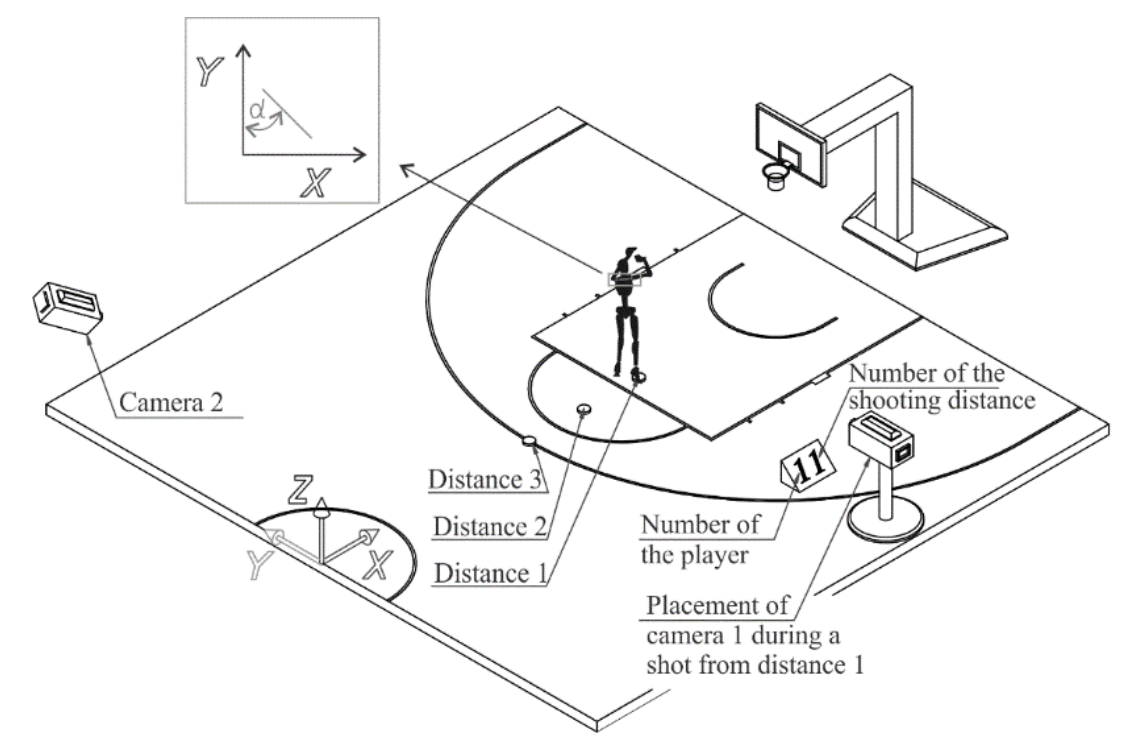

Figure 1

Measuring protocol, the coordinate system, and the angle of rotation of the shoulder axis.

Figure 2

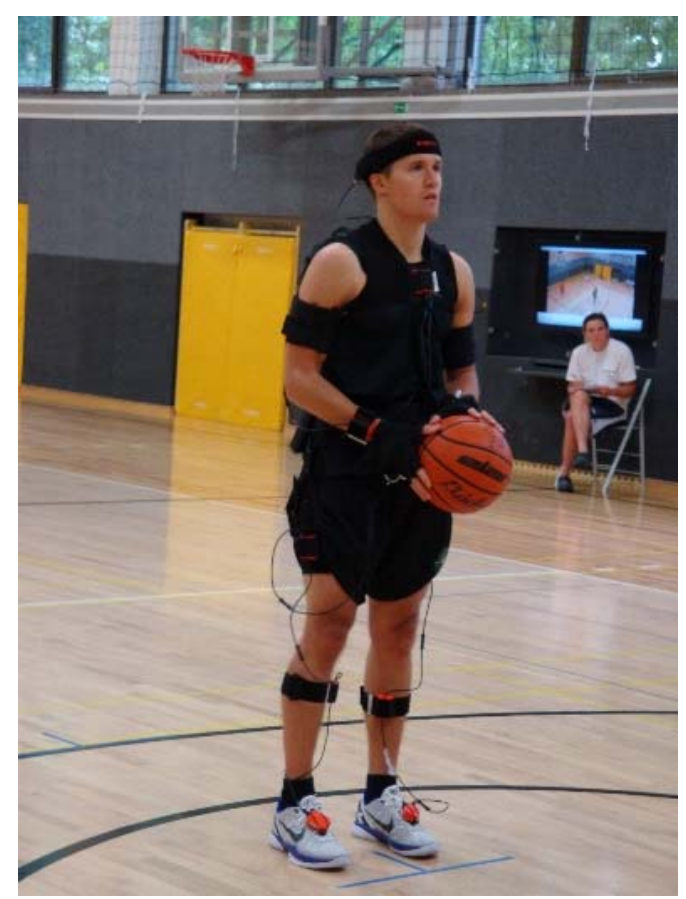

Jump shot with the MVN suit. 

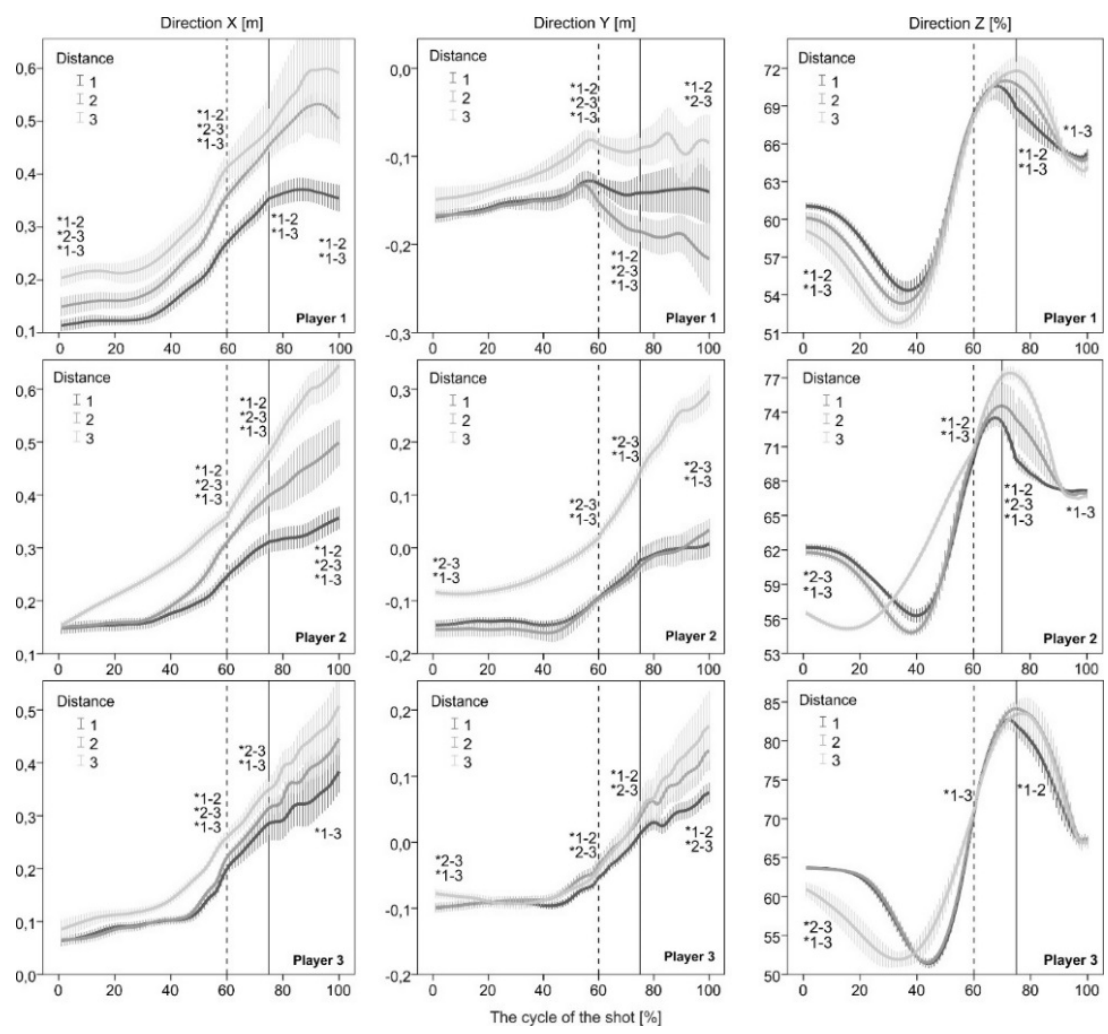

Figure 3

Average movement of the CoM. The dotted line on the $x$-axis represents the take-off and the solid line represents the time of ball release. The asterisk (*) marks the two distances that show significant differences in a particular moment.
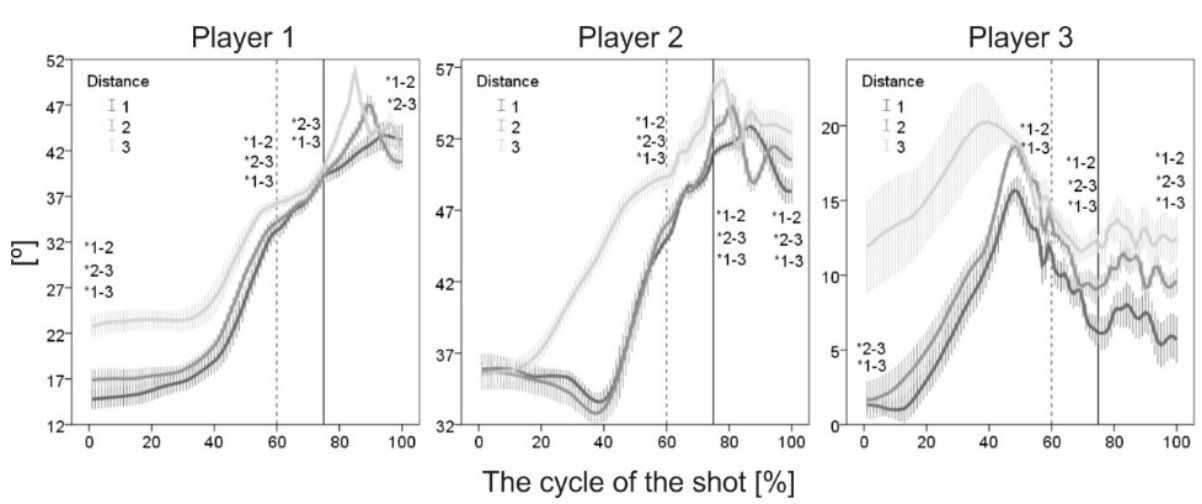

Figure 4

Average rotation of the shoulder axis and its confidence interval. The dotted line on the $x$-axis represents the take-off and the solid line the time of ball release. The asterisk $\left(^{*}\right)$ marks two distances showing significant differences in a particular moment. 


\section{Discussion}

The main findings of the study were that the movement before the ball release is shorter when increasing the distance, while it is prolonged after the ball release if the distance is increased. When the distance from the basket was increased, players decided on a longer jump towards the basket. All participants released the ball when falling down (after achieving the highest point of the jump) when shooting from the shortest and from the middle distance. In the lateral direction (which has not been investigated so far) the differences were most significant. Although the patterns of adjustment of the trajectory of the CoM and the shooting arm while shooting from different distances were different, it can be generalized that the deviation to the left was most significant while shooting from the largest distance. The results also showed that the rotation of the shoulder axis in the transverse plane, was greatest when shooting from the longest distance (especially in the preparation phase). In our participants' values (despite the homogeneous sample) differed quite significantly, thus caution is needed when making generalizations. The results demonstrated that even elite basketball players use different styles and techniques while performing a jump shot. Nevertheless, there are the already mentioned characteristics that are common to all when we increase the distance of shooting.

The results of this study show that during the shot, movements towards the basket (anteroposterior direction) increase with the increased distance (Figure 3). These changes were proportional for all three players while shooting distance was increased. The average shift CoM at the time of ball release from the longest distance was 28,33 and $26 \mathrm{~cm}$. These results are in line with the study by Okazaki and Rodacki (2012) who also had a sample of adult basketball players. Their shift at the time of ball release (when shooting from a distance of $6.75 \mathrm{~m}$ ) was $30 \mathrm{~cm}$. It is a bit surprising that these values are even higher than those of 15-year-old basketball players, where the shift at the time of ball release reached up to $25 \mathrm{~cm}$ when shooting from a distance of $6.75 \mathrm{~m}$ (Podmenik et al., 2015).

It is interesting that the greatest difference in the longest distance, when compared with the other two, lies in the mediolateral direction, which follows the direction of the baseline of the basketball court. This finding is novel, because this coordinate was not considered in previous studies that performed only 2D kinematic measurements in the sagittal plane (Elliot, 1992; Okazaki and Rodacki, 2012; Satern, 1993). As we can see in Figure 2, movement in this direction substantially differed among shooting distances and among players. After the take-off of player no. 1, deviation to the right was observed when shooting from the middle distance and deviation to the left when shooting from the longest distance. The pattern of the trajectory of the CoM of player no. 2 was similar when shooting from the shortest and the middle distance, but when he shot from the longest distance the curve was significantly moved to the left $(p<.05)$. Player's no. 3 curve of the trajectory of the CoM was rather unique. The deviation to the left increased proportionally with the shooting distance. Despite the observed patterns in the X-direction with the shooting distance, no such patterns were present in the Y-direction, and each player exhibited his unique patterns in that direction.

According to previous studies, the maximum height and the release height of the $\mathrm{CoM}$ decreased with younger players when increasing the shooting distance from the basket (Miller and Bartlett, 1993; Podmenik et al., 2015), which is not in line with our findings. At present, the maximum height of the $\mathrm{CoM}$ and the release height of the CoM increased when the shooting distance was increased in two players. In one case (player no. 3) the maximum height of the CoM and the release height of the CoM were highest when shooting from the middle distance. The same pattern as in the maximum height of the $\mathrm{CoM}$ and the release height of the CoM was found with the release height of the shooting hand (Table 1). Nevertheless, we should be aware that player no. 3 reached the highest values in the maximum height of the CoM and in the release height of the CoM when shooting from all three distances. Only his maximum height and release height of the CoM exceeded $80 \%$ of body height and his height of the release arm exceeded $120 \%$ of body height.

During the jump shot it is only at and around the peak of the jump that relatively the most stable frame of reference exists as velocity in the vertical direction is almost zero (Oudejans, 
2002). It was reported that elite basketball players take advantage of this stable condition at the time of ball release (Oudejans, 2002). Our study demonstrated more details regarding ball release with coordination of the peak jump. Even though our participants were elite basketball shooting guards, they did not, when looking at all three distances, coordinate the ball release with the peak of the jump in the same manner. At this point we must emphasise that nowadays some elite basketball players (such us Stephan Curry one of the best jump shooters in the NBA) perform single motion jump shots, which are characterized by a quick release executed immediately after the take-off. Similar shots are often performed by younger players as well. In general, we witnessed one key change in the movement of the CoM when our findings are compared with the younger players. While 15year-old basketball players reach maximum height before the ball release $(-.05 \mathrm{~s}$; the shortest distance), at the time of the ball release (the middle distance), and after the ball release $(.03 \mathrm{~s}$; the longest distance) (Podmenik et al., 2015), the situation slightly differs when it comes to elite players. When shooting from the shortest and middle distance, the latter perform the shot in the phase of falling down (after achieving the highest point of the jump). In our case, this was also true of one player while shooting from the longest distance $(-.03 \mathrm{~s})$, while the other two players performed the ball release before reaching the maximum height $(.002 \mathrm{~s}, .027 \mathrm{~s})$. The reason for performing the ball release after the peak of the jump is most likely due to the fact that elite basketball players are physically stronger. The belief that shots from the shortest distance are performed from the highest point (Oudejans, 2002) did not apply to youth players (Podmenik et al., 2015) nor to elite basketball players. Whatever the reason for this type of shot may be, it is obvious that players have automated this kind of strategy of shooting at the basket, as they perform the shots in the same way under in laboratory conditions, where they are not under pressure to score a field goal and are not being blocked by the opposing player.

Before performing the jump shot (before the take-off), the body rotates in the transverse plane. Players with a right shooting hand have their right part of the body placed before the left part. This is in line with the prevailing professional doctrine, which states that players place the right foot a half of foot before the left one when shooting at the basket (this applies to right-handed players) (Wissel, 2004). Some claim this is the most important factor of a successful shot (Miller and Bartlett, 1993) and should amount between 29 and $55^{\circ}$ in the preparatory phase. Miller and Bartlett (1996) have discovered a smaller rotation, which ranges between 16 and $21^{\circ}$ at the time of ball release. Our study shows great differences between participants (Figure 4), but all three performed a rotation of the body in the transverse plane, where they showed the greatest rotation at the longest distance. Therefore, the importance of the rotation increases with the distance. It ensures the anteroposterior stability and at the same time the rotation is used to propel the ball. It should supposedly also make the alignment of the shoulder, the elbow, and the wrist with the eyes easier (Hay, 1994), which could potentially increase accuracy.

There remains the possibility that the used measuring technology could have influenced the execution of the shots because of the sensors that where placed on the body. However, each individual sensor only weighs $30 \mathrm{~g}$ and it enables a direct measurement of the chosen variables. Participants did not complain about the discomfort related with the measuring equipment. In addition, they had quite a lot of time to warm up, practice the shots, and to adapt.

The current research provides unique information about the jump shot technique (kinematics) of elite basketball players, especially in the lateral direction. For these players the results demonstrated that changes in the trajectory of the CoM occurred in all three axis, showing the importance of analysing full body $3 \mathrm{D}$ kinematics and not only planar movements which was mostly the case in the past. In particular, gradual changes in the $X$ direction, predictable changes in the $Z$ direction and very specific changes in the $Y$ direction, which are different for each particular player occurred. Nevertheless, to fully comprehend the importance of movements in the medio-lateral direction future studies are needed. 


\section{Acknowledgements}

This study was conducted within the framework of the research programme "Kinesiology of the Monostructural, Polystructural and Conventional Sports" under the leadership of Milan Čoh, PhD. The studie complied with the current laws of the country in which they were performed. All authors declare no conflict of interest.

\section{References}

Button C, MacLeod M, Sanders R, Coleman S. Examining movement variability in the basketball free-throw action at different skill levels. Res Q Exerc Sport, 2003; 74(3): 257-269

Carter JEL, Ackland TR, Kerr DA, Stapff AB. Somatotype and size of elite female basketball players. J Sports Sci. 2005; 23(10): 1057-1063

Elliott B. A kinematic comparison of the male and female two - point and three - point jump shots in basketball. Aust J Sci Med Sport, 1992; 24(4): 111-118

Erčulj F, Bračič M. Differences between various types of elite young female basketball players in terms of their morphological characteristics. Kinesiologia Slovenica, 2010; 16(1/2): 51-60

Erčulj F, Štrumbelj E. Structural analysis of basketball shooting in Euroleague and Slovenian division 1 league. Šport, 2013; 61(3/4): 83-88

Hay JG. The Biomechanics of Sports Techniques. Englewood Cliffs, N. J.: Prentice Hall; 1994

Krüger A, Edelmann-Nusser J. Application of a full body inertial measurement system in alpine skiing: A comparison with an optical video based system. J Appl Biomech, 2010; 26: 516-521

Lamb P, Bartlett R, Robins A. Self - Organising Maps: An Objective Method for Clustering Complex Human Movement. International Journal of Computer Science in Sport, 2010; 9(1): 20-29

Miller S, Bartlett R. The effects of increased shooting distance in the basketball jump shot. J Sports Sci, 1993; 11: $285-293$

Miller S, Bartlett R. The relationship between basketball shooting kinematics, distance and playing position. J Sports Sci, 1996; 14: 243-253

Miller SA, Jackson SL. Kinematic comparative analysis of the coordination pattern of the basketball free throw. International Symposium on Biomechanics in Sport. 1995. Available at: https://ojs.ub.unikonstanz.de/cpa/article/view/2924; accessed on 17.04.2015

Oberle CD. Attentional style and susceptibility to distraction in novice and expert basketball players. Journal of Sports and Recreation Research and Education, 2010; 2(1): 1-7

Okazacki VHA, Rodacki ALF. Increased distance of shooting on basketball jump shot. J Sports Sci Med, 2012; 11: 231-237

Okazaki VHA, Rodacki ALF, Satern MN. A review on the basketball jump shot. Sports Biomechanics, 2015; 14, 190-205

Oudejans RRD, van de Langenberg RW, Hutter RI. Aiming at a far target under different viewing conditions: Visual control in basketball jump shooting. Hum Mov Sci, 2002; 21: 457-480

Podmenik N, Supej M, Kugovnik O, Erčulj F. Movement of the body's centre of mass during a jump shot related to the distance from the basket of young player. Kinesiologia Slovenica, 2015; 21: 21-33

Sampaio J, Janeira M, Ibáñez S, Lorenzo A. Discriminant analysis of game-related statistics between basketball guards, forwards and centres in three professional leagues. Eur J Sport Sci, 2006; 6(3): 173178

Sampaio J, McGarry T, Calleja-González J, Jiménez Sáiz S, Schelling i del Alcázar X, Balciunas M. Exploring Game Performance in the National Basketball Association Using Player Tracking Data. PLoS ONE, 2015; 10(7): e0132894. doi:10.1371/journal.pone.0132894 
Satern MN. Kinematic parameters of basketball jump shots projected from varying distances. International Symposium on Biomechanics in Sport, 1993. Available at:

https://ojs.ub.uni-konstanz.de/cpa/article/view/1736; accessed on 13.02.2013

Supej M. 3D measurements of alpine skiing with an inertial sensor motion capture suit and GNSS RTK system. J Sport Sci, 2010; 28(7): 759-769

Supej M. Moven 2 Excell [Computer program]. Ljubljana: self-publishing. 2012.

Supej M. New 3D measurement methodology for sport with emphasis on alpine skiing: MVN and RTK GNSS. Sport, 2011; 59(3): 171-178

Tang WT, Shung HM. Relationship between isokinetic strength and shooting accuracy at different shooting ranges in Taiwanese elite high school basketball players. Isokinet Exerc Sci, 2005; 13: 169-174

Walters M, Hudson J, Bird M. Kinematic adjustments in basketball shooting at three distances. International Symposium on Biomechanics in Sport, 1990. Available at:

https://ojs.ub.uni-konstanz.de/cpa/article/view/4308/4005; accessed on 25.05.2014

Wissel H. Basketball: Steps to success. Campaign: Human Kinetics; 2004

\section{Corresponding author:}

\section{dr. Nadja Podmenik}

Faculty of Sport, Gortanova 22, Ljubljana.

Tel: +386 40354 368,

E-mail address: npodmenik@gmail.com 